\title{
Analysis and Research on Risks of Dam-break Flood of Arch Dam
}

\author{
Xiaohang WANG \\ Dam Safety Management Department \\ Nanjing Hydraulic Research Institute \\ Nanjing, China \\ e-mail: xiaohangwang@nhri.cn
}

\section{Kefa ZHOU}

Dam Safety Management Department Nanjing Hydraulic Research Institute

Nanjing, China

e-mail: kfzhou@nhri.cn

\author{
Shichen ZHANG \\ Dam Safety Management Department \\ Nanjing Hydraulic Research Institute \\ Nanjing, China \\ e-mail: sczhang@nhri.cn
}

\author{
Cunyuan QIU \\ The Administration of Shi Men Reservoir in Hanzhong City \\ Shaanxi Province \\ Hanzhong, China \\ e-mail: 672180204@qq.com
}

\author{
Xiaowei YANG \\ The Administration of Shi Men Reservoir in Hanzhong City \\ Shaanxi Province \\ Hanzhong, China \\ e-mail: 598290825@ qq.com
}

\begin{abstract}
As the important non-engineering measure of safety management of reservoir dam, risk analysis on dam-break flood is of great importance in improving the level of safety management of dam in our country. It studies techniques of risk analysis on dam-break flood, i.e., dam-break mode of arch dam and calculation of break flow discharge process, compilation of flood risk diagram, assessment of potential losses, etc., discusses applicable conditions of subsection model method and overall model method for analysis on dam-break flood from the aspects of the sharp of reservoir area, development process of break hole, terrain materials of reservoir area, etc. in detail, and carries out analysis and research on risks of dam-break flood of Shimen Reservoir of Shaanxi Province: conducting analysis on dam-break flood through overall model method, estimating the potential losses of life through D\&M method, estimating direct economic losses through method of loss ratio and estimating indirect economic losses through coefficient method. The results show that risk analysis on dam-break flood is the important method for effectively decreasing or avoiding losses, and it shall select the most possible engineering condition with combination with facts of engineering to conduct risk analysis on dam-break flood.
\end{abstract}

Keywords-dam break; risk analysis; loss of life; economic loss

\section{INTRODUCTION}

As an important dam type, arch dam enjoys superiority of itself. Stability of arch dam is mainly supported by rock mass on both ends of dam rather than gravity of it, therefore, under the equal engineering conditions, with the same height of dam, engineering quantity of arch dam is only equivalent to $20 \%-50 \%$ of that of gravity dam, arch dam belongs to statically indeterminate structure, as long as the skewback is stabilized, when external load increases or part of arch dam begins to crack, the dam body can make proper adjustment according to stress with the overload capacity. Although dam-break event of arch dam seldom occurs, from the perspective of risk analysis, any engineering has no absolute safety. Compared with other types of dam, arch dam enjoys features of relatively high height, strong overload capacity, etc. which shall cause more serious result once dam break is caused.

China has the archest dams in the world, huge social benefits and economic benefits are gained from these reservoir dams, while risks are faced by the lower reaches. Years of practice show that only attaching importance to engineering measures and non-engineering measures can probability of dam break is effectively decreased and risks of the lower reaches of reservoir be decreased. As the important non-engineering measure of safety management of reservoir dam, risk analysis of dam-break flood not only is the effective measure for decrease of losses, but also has important significance for promotion of management level of reservoir dam.

\section{RISK ANALYSIS ON DAM-BREAK FLOOD}

\section{A. Analysis on Dam-break Flood of Arch Dam}

Analysis on dam-break flood mainly includes two parts: simulation of break hole and analysis on flood routing of the lower reaches.

Main task of simulation of break hole is process analysis of dam break and calculation of flow discharge process of break hole. During break of arch dam, water pressure 
expands to both sides, dam breaks instantaneously. Modes of dam break generally are whole break, or instantaneous whole break above one certain elevation, or instantaneous whole break of some dam sections, break time is very short. Water flow regime of instantaneous break mainly depends on action of gravity to make the water level around dam site have change, with forming discontinuous wave through displacement of water flow particle, peak flow discharge occurs at the starting time of dam break. Water surface of break hole is steep, which almost is up right, belonging to rapidly varied flow. At present, empirical formula methods of hydraulics mainly are adopted for calculation of maximum flow discharge during instantaneous break of arch dam, mainly including empirical formulas of A.Ritter, Schoklitch, XIE Renzhi, etc. From these methods, maximum flow discharge of break hole is related to factors, i.e., depth of water before dam, width of break hole and scallop height of dam body, etc., and these methods are mainly applicable to the reservoir area with the shape being approximate to limited long prism, with basically assuming reservoir area and downstream river channel as flat base and ignoring the effect of factors, i.e., terrain of reservoir area and features of capacity of reservoir as well as storage flood, etc. on flow discharge. On this basis, through empirical formula, gaining the time for completing discharge of reservoir water, through formula, through generalization of typical hydrograph, gaining the flow discharge process of break hole.

Analysis on flood routing of dam-break floor constantly adopts hydraulics method, main task is to calculate water level, flow velocity, arrival time of floor and lasting time of submersion, etc. of various places along the lower reaches in accordance with flow discharge process curve of dam site. Based on the process of whole dam break and flood routing, there are two kinds of methods for analysis on flood: subsection model method and overall model method. Subsection model method takes dam site as the link point of two up and down sections, adopts empirical formula to calculate the flow discharge process of dam site and takes it as the upper boundary for calculation of flood routing of the lower reaches. The method is not affected by time-dependent shape of break hole, but it can only be applicable to free effluent boundary. Overall model method takes upstream reservoir area of dam address, dam site and downstream river channel as a whole model into consideration, flow discharge process of dam site shall be caused by upstream and downstream water head difference of the original dam site, flow discharge curve of dam site shall be obtained automatically by procedure. The method can take factors, i.e., terrain of reservoir area and features of capacity of reservoir and storage flood, etc. into full consideration, which is applicable to various boundary conditions, such as free effluent, submersion effluent, etc., but it has relatively high accuracy requirement on terrain materials of reservoir area, and shape of break hole shall be basically with no change as time goes on.

\section{B. Risk Diagram of Dam-break Flood}

Risk diagram of dam-break flood is the visualized map with expression of features of flood risks by form of intuition and superposition of information of geographic elements, social economy, etc. with taking hydraulics model calculation of dam break flood routing as the basis. At present, risk diagram of dam-break flood not only includes elements of flood risks, i.e., submerged depth of the water, flow velocity of flood, lasting time of submersion, arrival time, etc., basic geographic information of river system, traffic, administrative division, land use, etc., information of hydraulic structures, i.e., dam, water gate, dike, etc.; but also includes social economic information of population, economy, etc. and distribution of disaster relief resources, i.e., medical treatment, rescue team, etc. With the development of GIS technology, risk diagram of dam-break flood is not just a visualized presentation of elements of flood risks, but it is the fusion of spatial information of elements of flood risks and attributes information related to them. Features of spatial surface features, such as population size of some regions, economic aggregate of various industries, quantity of various disaster relief resources, etc. as important attribute information are important parts constituting the risk diagram of dam-break flood as well.

\section{Case Study}

Shimen Reservoir is located at the place, $1.8 \mathrm{~km}$ above exit of Baohe River canyon, level 1 tributary of upstream Hanjiang River, with total storage capacity of 1098 million $\mathrm{m}^{3}$, dam belongs to concrete double-curvature arch dam with the largest height of dam of $88.00 \mathrm{~m}$. Geographical location of reservoir is extremely important, downtown of Hanzhong City is located at the place, $18 \mathrm{~km}$ of downstream dam, there are important traffic facilities, such as ShiyanTianshui Expressway, Baoji-Bazhong Expressway, BeijingKunming Expressway, Yangpingguan-Ankang Expressway, Xi'an-Chengdu high speed railway, 108 national road and 316 national road, etc. Normal pool level of reservoir reaches $618.00 \mathrm{~m}$; ground elevation nearby dike left bank of downtown of Hanzhong City is about $505 \mathrm{~m}$ with fall reaching over $110 \mathrm{~m}$. In case of break of reservoir, it will seriously threaten the safety of hundreds of thousands of populations and infrastructure of main urban areas of downstream Hanzhong City. The paper takes instantaneous whole break of engineering conditions of middle $1 / 2$ dam section of Shimen Reservoir (width of break hole is about $132 \mathrm{~m}$ ) as the analysis case of engineering.

Assessment and research of loss of life mainly have two types. One type is to establish function relationship among loss of life or loss ratio of dam break with various influence factors in accordance with statistic analysis of historical data of dam break, difference of model mainly is embodied in the difference of considered influence factors, mainly including factors of population size, alarming time, seriousness of dambreak flood, understanding level of risks population on disaster of dam break, etc. Representative models contain B$\mathrm{G}$ model [2-3] proposed by the U.S. Bureau of Reclamation, D-M model [4], Graham method, etc. The aforesaid models ignore the difference of spatial distribution of loss of life 
influence factor, and then the calculated result is caused with no regional difference. In view of this, scholars introduce circumstances simulation and GIS modeling approach and adopt models of analytical hierarchy process, neural network, grey relational degree, etc. to conduct assessment on loss of life of population at risk [6-8].

Economic losses of dam break include direct economic losses and indirect economic losses. Direct economic losses include economic losses caused by damages of reservoir project and various losses caused by direct submersion of dam-break flood which can be measured by currency. Direct economic losses can be calculated by loss ratio, indexes of damages length, area, etc., interruption time of economic activities, earnings losses of agriculture and spoliation losses of engineering facilities, etc. in accordance with types of losses or industries of occurrence. Indirect economic losses refer to losses which can be measured by currency excepting direct economic losses, generally adopting coefficient method, i.e., through typical sampling investigation, finding out the proportional relation between indirect economic losses and direct economic losses caused to different departments and units.

\section{CASE STUdY}

Shimen Reservoir is located at the place, $1.8 \mathrm{~km}$ above exit of Baohe River canyon, level 1 tributary of upstream Hanjiang River, with total storage capacity of 1098 million $\mathrm{m}^{3}$, dam belongs to concrete double-curvature arch dam with the largest height of dam of $88.00 \mathrm{~m}$. Geographical location of reservoir is extremely important, downtown of Hanzhong City is located at the place, $18 \mathrm{~km}$ of downstream dam, there are important traffic facilities, such as ShiyanTianshui Expressway, Baoji-Bazhong Expressway, BeijingKunming Expressway, Yangpingguan-Ankang Expressway, Xi'an-Chengdu high speed railway, 108 national road and 316 national road, etc. Normal pool level of reservoir reaches $618.00 \mathrm{~m}$; ground elevation nearby dike left bank of downtown of Hanzhong City is about $505 \mathrm{~m}$ with fall reaching over $110 \mathrm{~m}$. In case of break of reservoir, it will seriously threaten the safety of hundreds of thousands of populations and infrastructure of main urban areas of downstream Hanzhong City. The paper takes instantaneous whole break of engineering conditions of middle $1 / 2$ dam section of Shimen Reservoir (width of break hole is about $132 \mathrm{~m}$ ) as the analysis case of engineering.

\section{A. Simulation of Flow Discharge Process of Break Hole}

Dam of Shimen Reservoir is divided into 17 dam sections in total, central angle of dam is $43^{\circ} \sim 129^{\circ}$, mean radius is $72.6 \mathrm{~m} \sim 113.0 \mathrm{~m}$, arc height ratio is 2.3 , thicknessheight ratio is 0.31 . Reservoir belongs to reservoir of river valley type of mountainous area with length of reservoir area of $18 \mathrm{~km}$, width of break hole of $132 \mathrm{~m}$, width of break: length of break hole $=1: 136$, which cannot be simplified into limited long-prism reservoir with flat base, therefore, flow discharge of break hole of Shimen Reservoir is not calculated with adoption of empirical formula method, the paper adopts overall model method to conduct analysis on dam-break flood. Flow discharge of break hole shall be caused by upstream and downstream water head difference of original dam site, taking storage flood as the upstream boundary condition, flow discharge shall be automatically be solved by procedure, see Diagram 1. Through calculation, peak flow discharge of break hole is $74579.85 \mathrm{~m}^{3} / \mathrm{s}$, in case $\mathrm{t}=0$, then flow discharge will be rapidly decreased progressively.

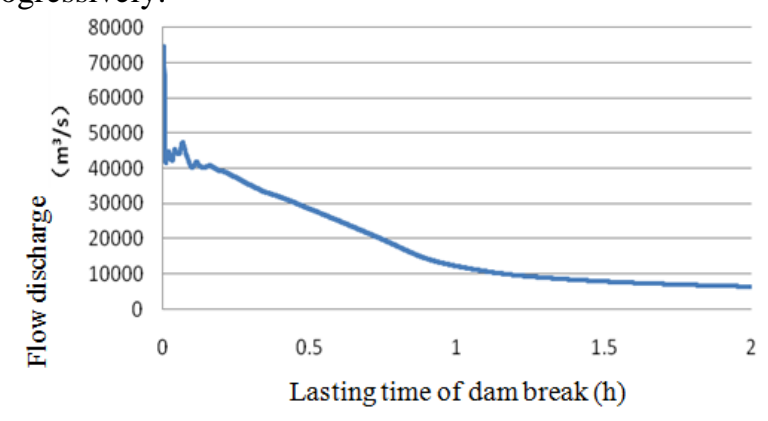

Figure 1. Flow Discharge of Break Hole

\section{B. Analysis on Flood Routing}

The paper adopts two-dimension hydraulics method to conduct calculation of downstream flood routing of Shimen Reservoir Dam. Mainly containing determination of calculation range, mesh generation and difference value, model setting, withdrawal of calculation results, etc.

During mesh generation, adopt the maximum area of mesh and the minimum angle of triangle to conduct control on mesh generation; during interpolation of mesh, separately set partition line for two sides of river channel, ensure separate interpolation of river channel and land, and avoid inaccurate interpolation elevation of neighboring mesh of river channel and land. For high narrow ground objects, such as river channel, dike, etc., the elevation is required to be set separately, and shall not participate in interpolation of mesh. For the conditions of road crossing river channel, intersection of river channel and land is required to be broken to guarantee that the model conforms to facts. For structures crossing over river, generalization is required in accordance with actual position and size, then operation rule of structures shall be set.

\section{Assessment on Potential Losses of Dam Break}

1) Estimation of loss of life: Adopt D\&M method to conduct calculation on LOL(people) of dam break, the formula is as follows:

$$
\mathrm{LOL}=\frac{P_{A R}}{1+13.277\left(P_{A R}^{0.440}\right) \exp \left(0.759 W_{T}-3.790 F+2.223 W_{T} F\right)}
$$

In the formula, WT is the alarming time (h); $P_{A R}$ is population at risk; $F$ is strength of flood, value range $0 \sim 1$.

Shimen Reservoir belongs to large reservoir of high dam of mountainous area, therefore, $\mathrm{F}=1$, the aforesaid formula can be approximately simplified as: 


$$
\mathrm{LOL} \approx 0.075\left(P_{A R}^{0.560}\right) e^{\left(-2.982 W_{T}+3.790\right)}
$$

Through statistical analysis, $P_{A R}=219005$, it shall calculate loss of life of dam break of Shimen Reservoir in accordance with the formula (2), taking WT as 0, 0.5, 1 and $2 \mathrm{~h}$, LOL of dam break obtained from calculation separately is $3249,732,165$ and 9 separately.

2) Estimation of economic losses: The paper conducts separate estimation on direct economic losses and indirect economic loss for dam break of Shimen Reservoir.

Direct economic losses mainly include five parts: losses of reservoir pivotal project, losses of fixed assets of the state and group, losses for stop production of industrial and mining enterprises, losses of resident households properties and losses of the first industry. Wherein, losses for stop production of industrial and mining enterprises shall be estimated in accordance with 4-month interruption time. For the rest parts, it shall conduct estimation on direct economic losses in accordance with loss ratio. Direct economic losses ratio shall adopt loss ratio curve [10] of various types of properties under the different conditions of submersion and depth of water analyzed and estimated by scientific and technical workers of our country in accordance with a large quantity investigation materials. In accordance with statistical yearbook materials of 2012, potential direct economic losses caused by dam break of Shimen Reservoir are estimated for about RMB14.17 billion, various economies losses are estimated, see Table I.

TABLE I. ESTIMATION OF VARIOUS ECONOMIES LOSSES (UNIT: RMB100 MILLION)

\begin{tabular}{|c|c|c|c|c|c|}
\hline $\begin{array}{c}\text { Losses of } \\
\text { reservoir } \\
\text { pivotal } \\
\text { project }\end{array}$ & $\begin{array}{c}\text { Losses of } \\
\text { fixed } \\
\begin{array}{c}\text { assets of } \\
\text { the state } \\
\text { and group }\end{array}\end{array}$ & $\begin{array}{c}\text { Losses for } \\
\text { stop } \\
\text { production } \\
\text { of industrial } \\
\text { and mining } \\
\text { enterprises }\end{array}$ & $\begin{array}{c}\text { Losses of } \\
\text { resident } \\
\text { households } \\
\text { properties }\end{array}$ & $\begin{array}{c}\text { Losses of } \\
\text { the first } \\
\text { industry }\end{array}$ & $\begin{array}{c}\text { Direct } \\
\text { economic } \\
\text { losses }\end{array}$ \\
\hline 7.90 & 74.46 & 39.45 & 18.62 & 1.27 & 141.70 \\
\hline
\end{tabular}

Adopt indirect loss coefficient (percent of indirect economic losses accounting for direct economic losses) method to conduct estimation on indirect economic losses caused to dam break of Shimen Reservoir, in accordance with related research result, indirect economic loss coefficient of dam break among various industries takes 0.63 [11] . Indirect loss caused by dam break of Shimen Reservoir is about RMB8.927 billion through calculation.

In conclusion, total economic losses caused by dam break of Shimen Reservoir are about RMB23.097 billion.

\section{CONCLUSION}

The paper conducts research on techniques of risk analysis on flood, i.e., calculation of break hole of arch dam, analysis on flood routing, drawing of risk diagram, assessment on losses of dam break, etc., summaries and analyzes related methods and techniques, proposes application conditions of subsection model method and whole model method for analysis on dam-break flood, and conducts detailed discussion. Taking Shimen Reservoir of Shaanxi Province as the example, analysis on dam-break flood is conducted by adopting whole model method, on the basis, potential loss of life and economic losses of dam break of Shimen Reservoir are estimated.

Loss of life is closely related to early warning time, we can know from estimation result of potential loss of life of Shimen Reservoir that improvement of early warning time can greatly reduce the loss of life. Because social economic development level of human is improved continually, population and various social properties value will be increased as time goes on, therefore, the losses caused by dam break of equal scales in different years to the society are different, especially for economic losses, the difference will be larger for different years.

Mode of dam break of arch dam is instantaneous dam break, peak flow discharge occurs at the starting time of dam break, once dam break occurs, it will make extreme influence on the lower reaches. As one main nonengineering measure, risk analysis on dam-break flood makes significant meaning for emergency management and emergency decision, in actual engineering, with combination of specific conditions of reservoir; select the most possible mode of dam break to conduct risk analysis on dam-break flood.

\section{ACKNOWLEDGMENT}

This work is supported by Project supported by the Nation Natural Science Foundation of China (Grant No.51509156, 41671504) and Non-profit Industry Financial Program of MWR (201501033).

\section{REFERENCES}

[1] Hydraulics and mechanics of fluids teaching and research section of Water conservancy and hydropower college of Wuhan university, "Hydraulic calculation manual (second edition)," Beijing: China Water Power Press, 2006.

[2] DeKay M L, McClelland G H, "Predicting Losses of life in Cases of Dam Failure and Flash Flood". Risk Analysis, Iss.2, pp.193-205, 1993.

[3] Brown C A, Graham W J, "Assessing the threat to life from dam failure," Paper No.88044 of the Water Resources Bulletin, American Water Resources Association, USBR, 1988. 12.

[4] Graham W J, "A simple procedure for estimating losses of life from dam failure," RESCDAM-LOL, Helsinki, 2001.

[5] Graham W J, "A procedure for estimating losses of life caused by dam failure," DSO-99-06, USBR, 1999.

[6] WANG Xiaohang, SHENG Jinbao, ZHANG Xingnan, "Research on pre-alarming model for loss of life due to dam-break base on GIS," Journal of Hydroelectric Engineering, Vol.30, Iss.4, pp.72-78, 2011.

[7] WANG Zhijun, GU Chongshi, ZHANG Zhijun, "Evaluation Method of Loss-of-life Caused by Dam Breach Based on GIS and Neural Networks Optimized by Genetic Algorithms". Geomatics and Information Science of Wuhan University, Vo.135, Iss.1, pp.64-68, 2010.

[8] WANG Zhijun, GU Chongshi, LIU Hongcai, "Assessment Method of Loss Caused by Dam-Break Based on GIS and SVM", Journal of Yangtze River Scientific Research Institute, Vol.25, Iss.4, pp.28-32, 2008 . 
[9] LI Lei, WANG Renzhong, SHENG Jinbao, etc. "Dam Risk Evaluation and Risk Management," Beijing: China Waterpower Press, 2006.

[10] JIANG Shuhai, FAN Ziwu, WU Shiqiang."Flood risk assessment and Flood control safety decision," Beijing: China waterpower press, 2005
[11] P.I. Hill, D. Cook, R.J. Nathan, P.A. Crowe, J.H. Green, M. Mayo."Development of a Comprehensive Approach to Consequence Assessment," ANCOLD Bulletin, 2011. 